\title{
Influence of operation temperature variations on NO measurements in low concentrations when applying the pulsed polarization technique to thimble-type lambda probes
}

\author{
S. Fischer ${ }^{1,2}$, D. Schönauer-Kamin ${ }^{1}$, R. Pohle ${ }^{2}$, M. Fleischer ${ }^{2}$, and R. Moos $^{1}$ \\ ${ }^{1}$ Department of Functional Materials, University of Bayreuth, Bayreuth, Germany \\ ${ }^{2}$ Corporate Technology, Siemens AG, Munich, Germany \\ Correspondence to: R. Moos (functional.materials@uni-bayreuth.de)
}

Received: 2 July 2015 - Revised: 10 November 2015 - Accepted: 11 November 2015 - Published: 23 November 2015

\begin{abstract}
By applying the pulsed polarization technique, a thimble-type lambda probe can be used as a $\mathrm{NO}_{x}$ sensor in the low ppm range. Due to the robustness of the sensor in harsh exhaust gas environments, this approach has many opportunities for application. The temperature operating range for best NO sensing properties is a crucial parameter. The sensor temperature changes with the ambient gas temperature, but can be stabilized actively by internal heating in a certain temperature range. This study evaluates in detail the temperature influence on NO sensitivity, so that an optimum operating point can be derived from these results using a dynamic measurement technique. Stepwise NO concentration changes between 0 and $12.5 \mathrm{ppm}$ in synthetic exhausts demonstrate the potential of the concept.
\end{abstract}

\section{Introduction}

Environmental issues like acid rain and smog are caused by oxides of nitrogen $\left(\mathrm{NO}_{x}\right)$, so that strong emission regulations have been introduced for automotive emissions. For active emission control of automotive exhausts, $\mathrm{NO}_{x}$ detection in the low ppm range is important - without cross-sensitivities to other exhaust components. Despite many approaches in the past years, which are reviewed in the literature (Zhuiykov and Miura, 2007; Fergus, 2007; Guth and Zosel, 2004), only one type of $\mathrm{NO}_{x}$ sensor has made it to series production. This sensor is a derivative of the planar oxygen sensor manufactured in planar zirconia ceramic technology (Riegel et al., 2002; Moos, 2005). Due to the complex setup of this amperometric double pumping cell (Siegberg and Kilinc, 2014; Kato et al., 1996), cost issues must always be considered, especially with respect to the low sensitivities of the sensor raw signal of only a few nA ppm ${ }^{-1}$ NO (Kato et al., 1996), which requires costly circuitry and may also lead to a reduced accuracy (Kim and Van Nieuwstadt, 2006).
The thimble-type lambda probe is a well-known robust and reliable sensor that can be operated especially in the exhausts of internal combustion engines between a few hundred ${ }^{\circ} \mathrm{C}$ and almost $1000{ }^{\circ} \mathrm{C}$ (Baunach et al., 2006). As shown in previous works, it is possible to operate a commercial thimble-type lambda probe as a promising NO sensor just by applying a so-called pulsed polarization technique (Fischer et al., 2010). For this method, voltage pulses of alternating signs with intermediate depolarization phases (Fischer et al., 2010, 2012a, 2013) are applied. The self-discharge voltage (open circuit voltage) after each polarization pulse is strongly affected if NO is present in the exhaust. Since the properties of this sensor element of oxygen ion conducting yttria stabilized zirconia (YSZ) with porous platinum electrodes also change widely with temperature, "temperature" is a parameter with a large influence on the sensor response to NO.

Thimble-type lambda probes can be heated internally by the already available internal rod-type heater so that the sensor temperature can be controlled independently of the outer 


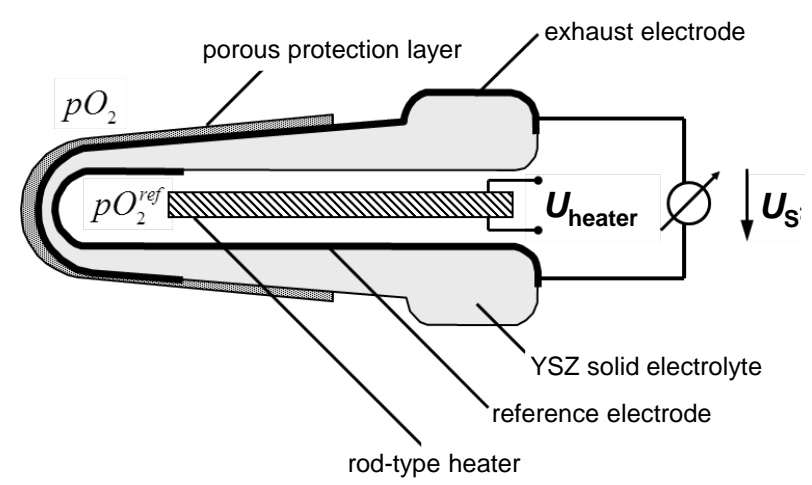

Figure 1. Thimble-type lambda probe (scheme, adapted from Moos, 2006).

exhaust gas temperature (in the case of a lower outer temperature compared to the desired sensor temperature).

This study raises and answers the question of whether the lambda probe can be applied as a NO sensor in a large temperature range only by controlling the heater voltage depending on ambient temperature. This information is essential for the development of an operating strategy and a possible sensor application. The target operation temperature is in the range of about $400^{\circ} \mathrm{C}$.

For that purpose, the discharge curves of the sensor after polarization pulses as well as polarization currents during voltage pulses are recorded at different external gas temperatures and internal heater voltages.

\section{Experimental}

\subsection{Measurement setup}

Thimble-type lambda probes are well known and have been described by many authors (Riegel et al., 2002; Moos, 2005; Baunach et al., 2006). The illustration of a commercial thimble-type sensor is shown in Fig. 1.

The porous Pt reference and exhaust electrodes on yttria stabilized zirconia (YSZ), which is an oxygen ion conductor at temperatures above $350{ }^{\circ} \mathrm{C}$, separate the reference and the exhaust side. Due to the thimble-type design, the atmosphere of the inner electrode is on a well-known oxygen partial pressure reference level $\left(p \mathrm{O}_{2}^{\text {ref }}\right)$. Considering the changing oxygen content at the outer exhaust electrode $\left(p \mathrm{O}_{2}^{\text {exhaust }}\right)$, a sensor voltage according to Nernst forms. It depends on the ratio of the oxygen partial pressure at both electrodes (Riegel et al., 2002):

$U_{\text {Nernst }}=\frac{R T}{4 F} \ln \frac{p \mathrm{O}_{2}^{\text {exhaust }}}{p \mathrm{O}_{2}^{\text {reference }}}$,

with the known temperature $T$, the universal gas constant $R$ and Faraday's constant $F$. The outer electrode is coated with a thick porous protection layer, mainly consisting of

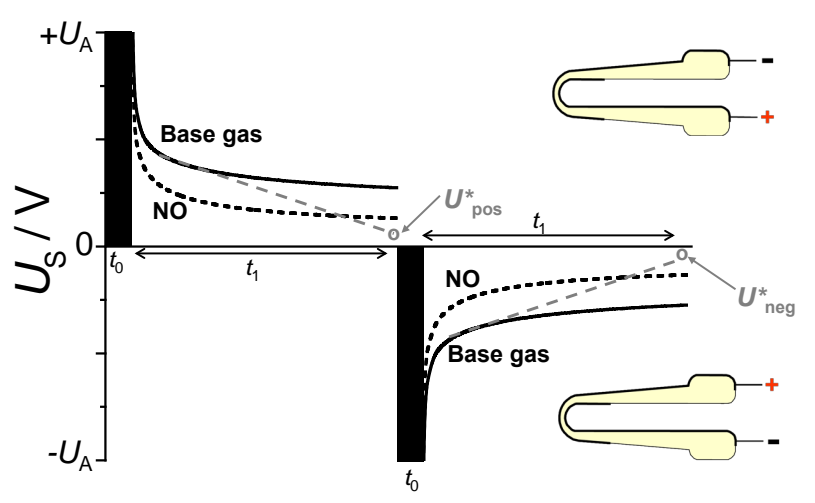

Figure 2. Scheme of the pulsed polarization technique with corresponding signs of electrode polarization of the thimble-type lambda probe and illustration of how $U^{*}$ is evaluated.

$\mathrm{MgAl}_{2} \mathrm{O}_{4}$ spinel to ensure long-term stability in the harsh exhaust gas environment. The minimum sensor temperature of $350{ }^{\circ} \mathrm{C}$ for sufficient oxygen ion mobility is controlled by applying a heater voltage ( $\left.U_{\text {heater }}\right)$ to an internal rod-type heater, so that a metering voltage $\left(U_{\mathrm{S}}\right)$ between the outer sensing and inner reference electrode occurs according to Eq. (1).

To evaluate the temperature range for NO sensing by applying the dynamic measurement technique, various temperatures are adjusted by different gas temperatures $T_{\text {gas }}$ from 300 to $450^{\circ} \mathrm{C}$ in $50^{\circ} \mathrm{C}$ steps without internal heating. Additionally, the sensor response is investigated at different heating voltages. For that purpose, $U_{\text {heater }}$ was varied from 0 to $10 \mathrm{~V}$ in $1 \mathrm{~V}$ steps, which are applied at a constant gas temperature $T_{\text {gas }}=350^{\circ} \mathrm{C}$.

The gas composition used as a baseline for the measurements contains $10 \%$ oxygen with a humidity level of $3 \%$ absolute and a flow rate of $1 \mathrm{Lmin}^{-1}$. The NO response is evaluated by adding $12.5 \mathrm{ppm}$ of this gas.

\subsection{Pulsed polarization technique}

The pulsed polarization technique is a dynamic measurement method. Voltage pulses of alternating signs but equal amplitudes and discharges pauses in between are applied (Fischer et al., 2010, 2012b). After polarization, the open circuit discharge curves are recorded during the discharge phase. Figure 2 illustrates a typical single-measurement process. The discharge curves are strongly dependent on the NO concentration in the exhaust. This is also schematically depicted in Fig. 2. The signs of the polarization pulses as related to the design of the thimble-type lambda probe are depicted as well. During the negative voltage pulse (as it is defined here), the negatively charged oxygen ions are pumped to the outer atmosphere driven by the higher potential of this electrode. During opposite polarization sign, the ions are transported to the inner reference electrode.

To obtain a single NO concentration value, for example at defined parameters $T_{\text {gas }}$ and $U_{\text {heater }}$ or at a defined gas com- 
position, the evaluation of the whole discharge curve with many measured points would be too time-consuming. Therefore, only one parameter characterizing the discharge curve is used. The slope of the discharge curves $\mathrm{d} U / \mathrm{d} t$, which is fitted between 2 and $3 \mathrm{~s}$ after the polarization pulse, is used as an indicator for the analyte concentrations in the investigated exhausts. The extrapolation to $10 \mathrm{~s}$ defines the sensor output signal, the voltage $U^{*}$. The process of how $U^{*}$ is evaluated is also illustrated in Fig. 2 for positive and negative polarization.

Many parameters of the dynamic measurement technique can be varied to optimize the setup for NO sensing. The optimum parameter for NO detection by the pulsed polarization method was found in a previous study by applying a polarization amplitude of $U_{\mathrm{A}}=2.5 \mathrm{~V}$ with a pulse duration of $t_{0}=1 \mathrm{~s}$ and a subsequent discharge time duration of $t_{1}=10 \mathrm{~s}$. Using these defined voltage pulses of alternating sign, high NO sensitivities in a low ppm range are measured as already shown previously (Fischer et al., 2010, 2012a, 2013).

In addition to discharge voltage evaluation between alternating polarizations, the polarization current $\left(I_{\text {pol }}\right)$ during the polarization pulses is recorded. The current value is temperature-dependent, since the resistance of the oxygen ion conducting YSZ changes. Therefore, this parameter can be used as a good temperature indicator.

\section{NO sensitivity at temperature variation}

As described in Sect. 2.1, the sensor temperature is varied actively using different heating voltages and passively only by changing the gas temperatures. The NO sensitivities are evaluated for each of these methods.

\subsection{Sensor operation temperature dependence due to gas temperature variations}

When increasing the ambient exhaust temperature, the sensor temperature changes accordingly. The polarization current curves during positive and negative polarization pulses are shown in Fig. 3 for gas temperatures in the range from $T_{\text {gas }}=300$ to $450^{\circ} \mathrm{C}$. For that investigation, the heater voltage $U_{\text {heater }}$ was set to zero, so that no additional heating occurred. Due to heat loss through the sensor mount, the sensor temperature is roughly $10-20^{\circ} \mathrm{C}$ less than the gas temperature. As already known from the literature (Fischer et al., 2013), the pulse voltage was $U_{\mathrm{A}}=2.5 \mathrm{~V}$ for a pulse duration of $t_{0}=1 \mathrm{~s}$.

The final values after $1 \mathrm{~s}$ were further evaluated. Due to high resistance at low temperatures, a current of only $35 \mu \mathrm{A}$ at $300{ }^{\circ} \mathrm{C}$ flows, which is too low for electrode polarization including charge separation. Only if the temperature exceeds about $350^{\circ} \mathrm{C}$ is the oxygen ion mobility of YSZ sufficiently high enough so that a noticeable and time-dependent polar-

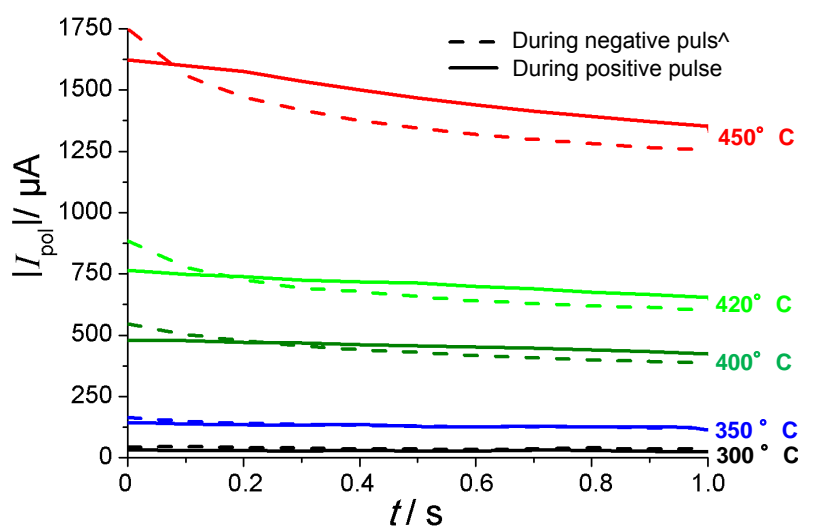

Figure 3. Polarization currents $I_{\text {pol }}$ during positive and negative pulses at various gas temperatures $\left(T_{\text {gas }}\right)$ as indicated.

ization current occurs. At $450^{\circ} \mathrm{C}$, the current is increased by a factor of 40 compared to $300^{\circ} \mathrm{C}$.

The current of both polarization processes with opposite signs can be separated into two phases. After a timedependent phase at the beginning, the current becomes almost stationary. The time dependency can be seen above $350{ }^{\circ} \mathrm{C}$. It is assumed that starting from that point, a sufficient electrode polarization with associated charge separation occurs. During the stationary current at the end of the polarization process, only oxygen ions were pumped through the ion-conducting YSZ without an effect on charge separation and polarization magnitude.

The temperature-dependent polarization currents for positive and negative voltage pulses are almost the same, but a closer look reveals differences in their time-dependent behavior. At the beginning of pulses, the absolute value of the current during negative polarization pulses is higher level and decreases more strongly with time compared to the opposite sign. The stationary current at the end of polarization is, on the other hand, clearly lower. This may be caused by two effects. The stationary current at the end of polarization, which can be interpreted as oxygen pumping through the ion conductor YSZ without an additional effect of polarization, is dependent on transport of oxygen to the electrode surface and removal of oxygen from the surface at the opposite electrode. These differences in oxygen transport during both polarization signs can be explained by different gas volumes, which are available for oxygen exchange. The reference atmosphere at the inside of the thimble-type sensor contains less gas volume so that the oxygen transport is limited compared to oxygen transport from the outer gas atmosphere to the inner reference electrode. The current differences at the beginning of the polarization, however, are caused by different depolarization voltages at the end of the depolarization pause. This is reported in detail in Fig. 5a and b below. After a positive polarization pulse, the voltage is at a higher voltage level (e.g., at $420^{\circ} \mathrm{C}: \sim+300 \mathrm{mV}$ ) compared to the opposite polariza- 


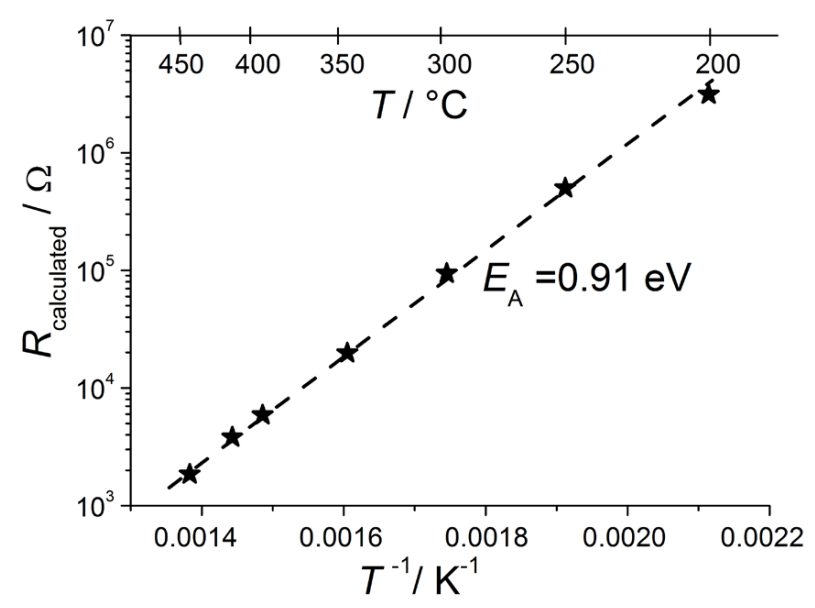

Figure 4. Arrhenius-like dependency of the calculated resistance with an activation energy of $0.91 \mathrm{eV}$.

tion sign (e.g., at $420^{\circ} \mathrm{C}: \sim+50 \mathrm{mV}$ ). The effective voltage difference $\left|U_{\text {end of epolarization }}-U_{\text {subsequent voltage pulse }}\right|$ to the subsequent $2.5 \mathrm{~V}$ voltage pulse is higher at negative polarization $[+300 \mathrm{mV}-(-2.5 \mathrm{~V})=2.8 \mathrm{~V}]$ compared to positive polarization $[50 \mathrm{mV}-2.5 \mathrm{~V}=-2.45 \mathrm{~V}]$. With this consideration the higher polarization current of $120 \mu \mathrm{A}$ at $420^{\circ} \mathrm{C}$ at polarization with a negative voltage pulse can be explained by the Ohmic law $\Delta I=\Delta U / R$ with respect to a resistance of $3 \mathrm{k} \Omega[\Delta I=350 \mathrm{mV} / 3 \mathrm{k} \Omega \sim 120 \mu \mathrm{A}]$.

Due to the Ohmic law $U=R \cdot I$, the temperaturedependent current correlates with a decreasing resistance. During polarization pulses with applied voltage amplitudes $U_{\mathrm{A}}=2.5 \mathrm{~V}$ each, the following resistances calculated from the final values of the polarization current $\left(I_{\mathrm{pol}}\right)$ after $1 \mathrm{~s}$ were further evaluated, and their temperature dependency is shown in the Arrhenius-like diagram of Fig. 4 according to $R_{\text {calculated }}=U_{\mathrm{A}} / I_{\mathrm{pol}}$. For that evaluation the mean values after both polarization signs are used.

The activation energy of $0.91 \mathrm{eV}$ agrees with the literature and is typical for $8 \mathrm{~mol} \%$ stabilized zirconia (Badwal, 1992).

After a polarization pulse of $1 \mathrm{~s}$, the self-discharge curves (open circuit voltages) are recorded for $10 \mathrm{~s}$ between the pulsed voltages with alternating sign as shown in Fig. 5a and $b$.

At temperatures below $300^{\circ} \mathrm{C}$, discharging after applied voltage pulses is very fast after both polarization signs, so that already $1 \mathrm{~s}$ after the applied voltage pulse voltages, only a few $10 \mathrm{mV}$ occur. These measurements are not shown here, because at this low temperature regime almost no oxygen ion conductivity exists and polarization is negligible. At $300^{\circ} \mathrm{C}$, a polarization including charge separation occurs, so that a distinct discharge voltage is measured after both polarization signs, whereby the voltage after a positive polarization sign is $50 \mathrm{mV}$ higher. This polarization correlates with a significant polarization current as already discussed.
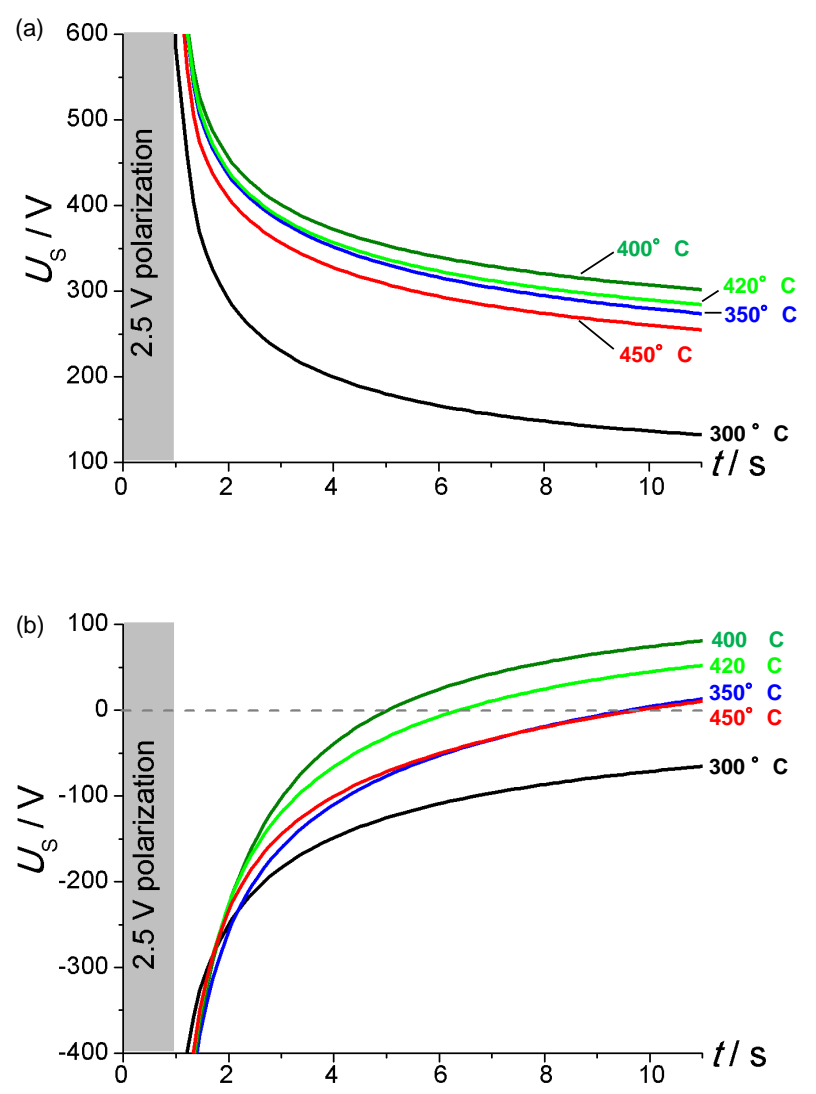

Figure 5. (a) Discharge voltage after positive voltage pulse at various temperatures. (b) Discharge voltage after negative voltage pulse at various temperatures.

After positive voltage pulses, the voltage is shifted to a more positive voltage up to $400^{\circ} \mathrm{C}$, so that the discharging is delayed further on by increasing temperature. However, it is apparent from observing alternating polarization signs that there is another underlying effect due to the completely different behavior after negative voltage pulses. Due to oxygen contents of $10 \%$ at the outer electrode and $20 \%$ at the reference electrode, an offset voltage occurs starting from this temperature range. After negative voltage pulse, the offset voltage is visible at $350{ }^{\circ} \mathrm{C}$ and especially at $400{ }^{\circ} \mathrm{C}$, with a corresponding voltage of $80 \mathrm{mV}$ after $10 \mathrm{~s}$.

This offset voltage occurs due to the Nernst Eq. (1) $U_{\text {Nernst }}=\frac{R T}{4 F} \ln \frac{p \mathrm{O}_{2}^{\text {exhaust }}}{p \mathrm{O}_{2}^{\text {ref }}}$, which indicates the oxygen gradient between the electrodes and increases with temperature. Thus, the same voltage in sign and amplitude overlies the whole discharge curve at temperatures at $350^{\circ} \mathrm{C}$ and higher.

The slowest discharge occurs at $400^{\circ} \mathrm{C}$ with a corresponding voltage of $300 \mathrm{mV}$ after $10 \mathrm{~s}$. At higher temperatures (420 and $450^{\circ} \mathrm{C}$ ) the sample discharges faster for both polarization signs. The resistance $R$ decreases by further increasing temperatures (cf. Fig. 4), which leads to the observed faster discharge. At these high temperatures, the voltage decay is 


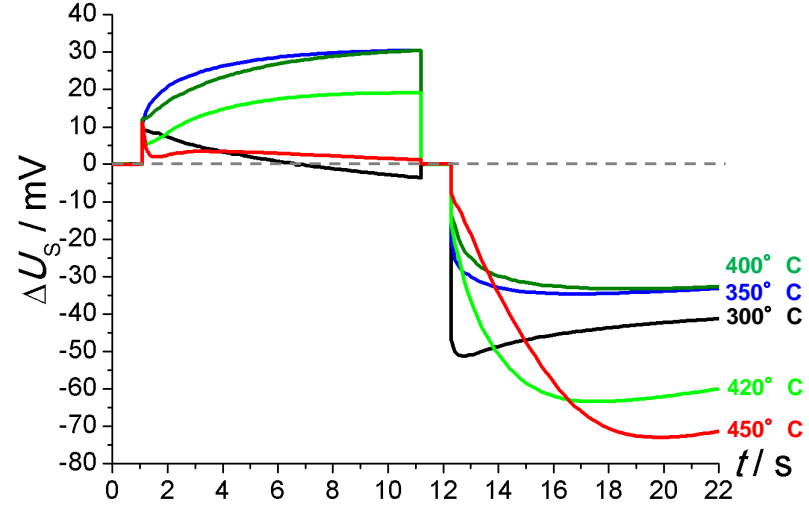

Figure 6. Voltage differences $\Delta U_{\mathrm{S}}$ with $12.5 \mathrm{ppm}$ compared to a measurement without $\mathrm{NO}$ in the base gas. 1-11 s: discharge after positive polarization. $12-22 \mathrm{~s}$ : voltage difference after negative polarization. Parameter: $T_{\text {gas }}$.

accelerated despite the strong polarization and overlying offset voltage. Thus, the decreasing resistance dominates the discharge behavior and the Nernst voltage is only less visible.

The main question is, however, how the temperature variation influences the NO sensitivity. For that purpose, $12.5 \mathrm{ppm}$ $\mathrm{NO}$ are dosed additionally to the base gas. To evaluate the NO effect on the discharge voltage, the voltage differences $\Delta U_{\mathrm{S}}(t)=U_{\mathrm{S}}^{\text {base gas }}(t)-U_{\mathrm{S}}^{12.5 \mathrm{ppm} \mathrm{NO}}(t)$ between the curves with $\mathrm{NO}$ and without $\mathrm{NO}$ in the base gas are calculated for the whole discharge process as shown in Fig. 6.

The voltage differences regarding $12.5 \mathrm{ppm}$ NO are different for both polarization signs and are dependent on the discharge time. At the lowest investigated temperature of $300^{\circ} \mathrm{C}$, almost no effect of $\mathrm{NO}$ after positive polarization occurs, whereas after opposite polarization sign, a voltage difference of around $40-50 \mathrm{mV}$ occurs. The maximum signal is measured at the beginning of the discharge and decreases later slightly. At higher temperatures $\left(350-400^{\circ} \mathrm{C}\right)$ the time-dependent voltage differences $\Delta U_{\mathrm{S}}$ are similar in curve shape and amplitude for both polarizations of opposite sign. This corresponds to accelerated discharging in NOcontaining atmospheres, in contrast to the base gas.

After positive voltage, the response to NO decreases when the temperature is further increased, so that at the highest investigated temperature of $450^{\circ} \mathrm{C}$ there is only an almost constant voltage difference $\Delta U_{\mathrm{S}}$ of a few $\mathrm{mV}$. In contrast to that, the NO effect after negative polarization voltage is markedly increased at temperatures above $400^{\circ} \mathrm{C}$, so that a strong time-dependent voltage response is measured. The maximum voltage difference regarding $12.5 \mathrm{ppm} \mathrm{NO}$ occurs at $450^{\circ} \mathrm{C}$ and it is about $70 \mathrm{mV}$ at the end of the discharge time.

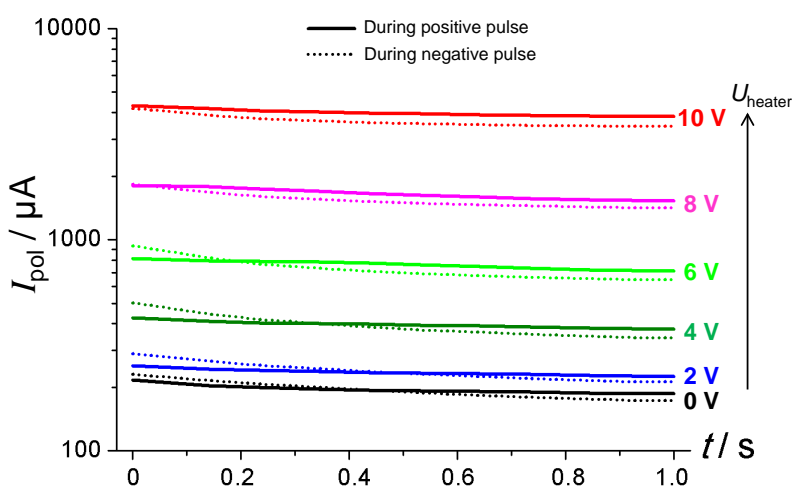

Figure 7. Polarization currents $I_{\text {pol }}$ (logarithmic scale) at various heater voltages and $T_{\text {gas }}=350^{\circ} \mathrm{C}$.

\subsection{Sensor operation temperature dependence due to heater voltage variations}

Applying a defined heater voltage is an alternative method to vary the sensor operation temperature. The active heating of the sensor causes a temperature difference $\Delta T$ between the inner and outer electrodes, in contrast to passive heating by changing the gas temperature as described in Sect. 3.1. To reduce this temperature difference $\Delta T$ and an associated thermoelectric voltage overlaying the discharge curves, the ambient gas temperature was set to $350{ }^{\circ} \mathrm{C}$ and the heater voltage was varied in $1 \mathrm{~V}$ steps between 0 and $10 \mathrm{~V}$. The polarization current was measured during polarization pulses of $1 \mathrm{~s}\left(U_{\mathrm{A}}=2.5 \mathrm{~V}\right)$. The results are plotted in Fig. 7; for clarity reasons, only results for even heater voltages are displayed.

With increasing heater voltages, the current increases as well, from almost $200 \mu \mathrm{A}$ without additional heating at a gas temperature of $350{ }^{\circ} \mathrm{C}$ up to about $4 \mathrm{~mA}$ with an additional heating voltage of $10 \mathrm{~V}$. In agreement with Fig. 3, the polarization current is time-dependent at temperatures of $350^{\circ} \mathrm{C}$, which corresponds to the measurement without active heating. By increasing the temperature, the time dependency becomes stronger, so that a current difference of $800 \mu \mathrm{A}$ is recorded between the beginning and the end of polarization pulse at a heating voltage of $10 \mathrm{~V}$ (due to the logarithmic scaling of the ordinate, this effect is barely visible in Fig. 7). The difference between the opposite polarization signs is less marked compared to the gas temperature influences, but still noticeable. Thus, the same explanation as before can be supposed: the various gas volumes, which are available at outer and inner electrodes, and the different amount of pumped oxygen ions causes the differences.

As before, the resistance $R$ is calculated from the polarization current during the polarization pulse.

Due to the temperature increase, the resistance $R_{\text {calculated }}$ drops down from nearly $13 \mathrm{k} \Omega$ without active heating to $630 \Omega$ at $U_{\text {heater }}=10 \mathrm{~V}$ (Fig. 8). If one compares the resistances with gas temperature variation with the one shown in Fig. 4 , the highest investigated temperature of $450^{\circ} \mathrm{C}$ corre- 


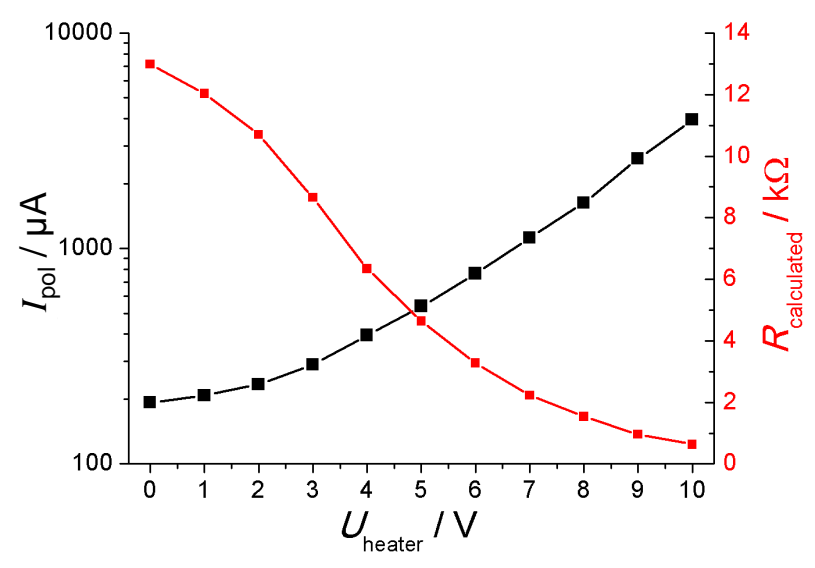

Figure 8. Influence of the heater voltage on the polarization current $I_{\text {pol }}$ and the calculated resistance $R_{\text {calculated }}$ at $T_{\text {gas }}=350^{\circ} \mathrm{C}$.
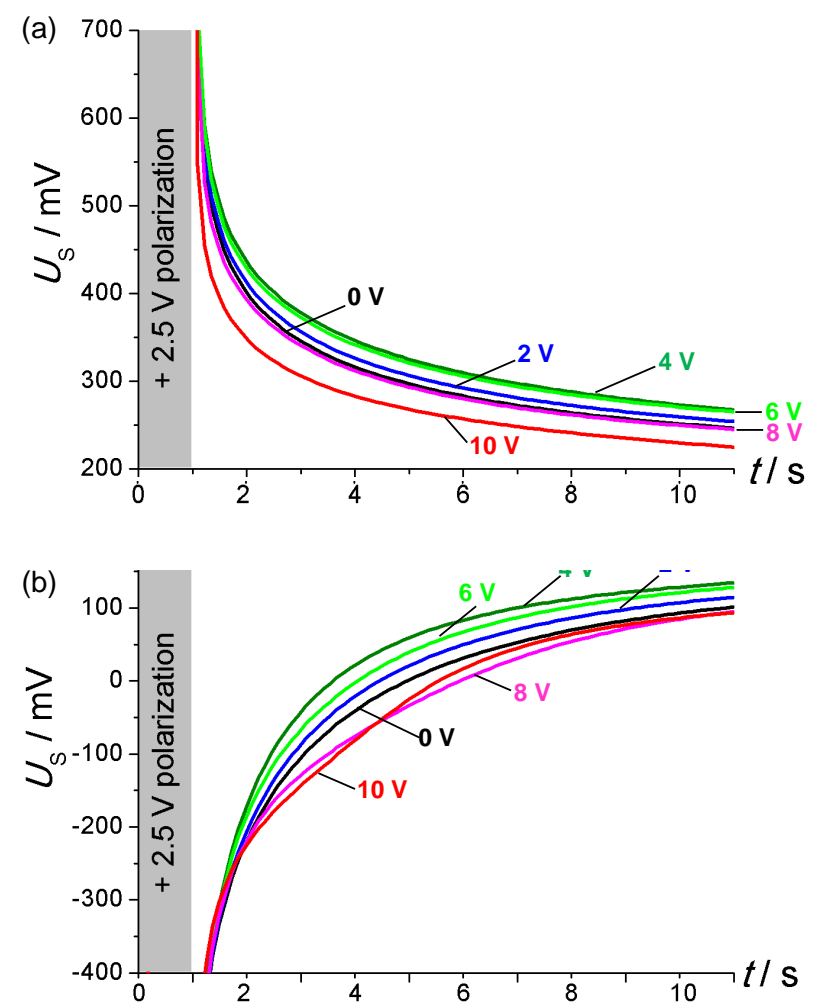

Figure 9. (a) Discharge voltage after positive voltage pulse at various heater voltages and $T_{\text {gas }}=350^{\circ} \mathrm{C}$. (b) Discharge voltage after negative voltage pulse at various heater voltages and $T_{\text {gas }}=350^{\circ} \mathrm{C}$.

sponds to an additional heating voltage of about $8 \mathrm{~V}$, in conjunction with a gas temperature of $350^{\circ} \mathrm{C}$.

The influence of the active heating on the discharge curves at base gas is shown in Fig. 9a and b for both polarization signs.

As shown in the section before, the discharge curves after opposite signs are not symmetrical with the zero line due to the non-symmetric sensor design and the overlaying offset voltage according to Nernst. Without additional active heating, the discharge curves are equal to the curve for $350^{\circ} \mathrm{C}$ shown in Fig. 5a and b, including strong polarization due to sufficiently high charge transport. The discharge curve of $4 \mathrm{~V}$ is on the most positive voltage level and almost equal to the results obtained for $400^{\circ} \mathrm{C}$. Furthermore, the polarization currents also agree quite well.

At heater voltages up to $4 \mathrm{~V}$ both discharge curves are shifted to more positive voltages. With increasing sensor temperature, a Nernst voltage according to Eq. (1) forms due to the oxygen partial pressure difference between both electrodes. It adds to the open circuit voltage.

In contrast to temperature variation only by gas temperature, an additional offset voltage caused by active heating can be seen. We assume that a thermoelectric voltage occurs due to the temperature difference between inner and outer electrodes generated by the rod-type heater at the inside of the thimble-type lambda probe. Furthermore, heating voltages above $4 \mathrm{~V}$ cause a faster discharge after both polarization signs, which agrees with the aforementioned results. The decreasing resistance of the ion conductor with higher temperatures causes this accelerated discharging. Only at the highest voltage of $10 \mathrm{~V}$ is the curve shape after negative voltage pulse changed compared to $8 \mathrm{~V}$, but at the end of discharging the voltages are both about $90 \mathrm{mV}$.

Again, the sensor response to NO when applying different heater voltages is evaluated by the voltage difference $\Delta U_{\mathrm{S}}(t)=U_{\mathrm{S}}^{\text {base gas }}(t)-U_{\mathrm{S}}^{12.5 \mathrm{pp} \mathrm{NO}}(t)$. The results are shown in Fig. 10 (analogously to Fig. 6).

In good agreement with temperature variation results that were obtained when solely the gas temperature was varied, discharging in a NO-containing atmosphere is also faster and the temperature dependencies are also almost the same. After positive voltage pulses, the voltage difference between $12.5 \mathrm{ppm} \mathrm{NO}$ in the base gas and the base gas continuously decreases with increasing heater voltages. At heater voltages of 8 and $10 \mathrm{~V}$, almost no NO effect can be seen, so that the discharge curves are almost equal, except for a few $\mathrm{mV}$.

After negative polarization pulses, the NO effect is present for all investigated heating amplitudes. Without active heating, a maximum voltage difference of $20 \mathrm{mV}$ occurs, which increases up to almost $120 \mathrm{mV}$ at $8 \mathrm{~V}$. All curves in NO discharge faster compared to the base gas. The NO effect increases with temperature up to a heating voltage of $8 \mathrm{~V}$. Additionally, the evaluated voltage difference increases with discharging time at higher temperatures. Applying higher heater voltages $(10 \mathrm{~V})$, the NO influence is lower and the maximum voltage difference is shifted to shorter discharging times.

All in all, the highest NO sensitivity is achieved by applying an additional heating voltage of $8 \mathrm{~V}$ at a gas temperature of $350^{\circ} \mathrm{C}$, so that a sensor response of about $120 \mathrm{mV}$ occurs as a response of $12.5 \mathrm{ppm} \mathrm{NO}$.

The NO sensitivity to different NO concentrations is evaluated for $0.5-12.5 \mathrm{ppm}$ NO. The sensor characteristics were 
Table 1. Dependency of the sensitivity to NO for several heater voltages, each after positive and negative voltage pulse. $T_{\text {gas }}=350{ }^{\circ} \mathrm{C}$.

\begin{tabular}{lrrrrrr}
\hline$U_{\text {heater }} V$ & 0 & 2 & 4 & 6 & 8 & 10 \\
\hline $\begin{array}{l}\text { NO sensitivity after positive } \\
\text { pulse in mV decade }\end{array}$ & 20.0 & 22.0 & 24.9 & 15.9 & -3.1 & -4.8 \\
$\begin{array}{l}\text { NO sensitivity after negative } \\
\text { pulse in mV decade }\end{array}$ & -12.0 & -14.0 & -21.5 & -56.7 & -88.0 & -50.7 \\
\hline
\end{tabular}

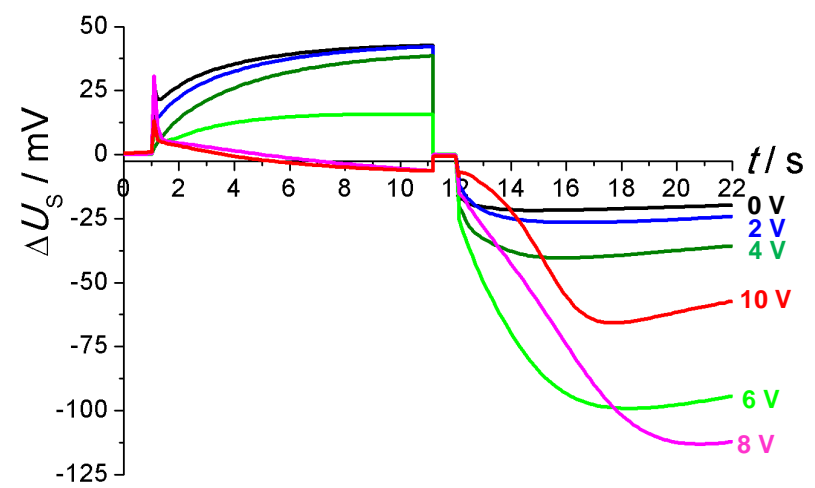

Figure 10. Voltage differences $\Delta U_{\mathrm{S}}$ with $12.5 \mathrm{ppm}$ NO in the base gas compared to a measurement without NO in the base gas. 1$11 \mathrm{~s}$ : discharge after positive polarization. $12-22 \mathrm{~s}$ : voltage difference after negative polarization. $T_{\text {gas }}=350^{\circ} \mathrm{C}$. Parameter: heater voltages.

obtained by evaluating the voltage difference after $10 \mathrm{~s}$ (right before the next polarization starts) between the curve in the base gas with and without NO. The sensor output in Fig. 11 is defined by $\Delta U_{10 \mathrm{~s}}=U_{10 \mathrm{~s}}^{\mathrm{NO}}-U_{10 \mathrm{~s}}^{\text {base gas }}$.

The characteristics show a semi-logarithmic dependency for all investigated heater voltages at NO concentrations above $1 \mathrm{ppm}$. The deviations at even lower NO concentrations from the semi-logarithmic behavior may be due to inaccuracies when dosing such small amounts of NO.

As discussed, the NO sensitivity decreases with increasing heater voltage after a positive voltage sign, whereas after the opposite polarization sign, the influence is vice versa. The highest sensitivity of $-88.0 \mathrm{mV}$ per decade NO is achieved at a heater voltage of $8 \mathrm{~V}$ after negative voltage pulses. Using these polarization parameters, there is almost no response after positive voltage pulses. The NO sensitivities at different heater voltages after both polarization signs are summarized in Table 1.

As illustrated in Fig. 12, the evaluation of $\Delta U^{*}$, which is described in Sect. 2.2 and illustrated in Fig. 2, can be considered a very suitable sensor signal. Although only the slope of the discharge curve between 2 and $3 \mathrm{~s}$ after voltage pulse is determined every $22 \mathrm{~s}$ (the cycle time contains $1 \mathrm{~s}$ for polarization and $10 \mathrm{~s}$ for discharging for each polarization sign), the NO gas dosing program, which consists of 5 min long steps for each concentration, is reflected very clearly, espe-
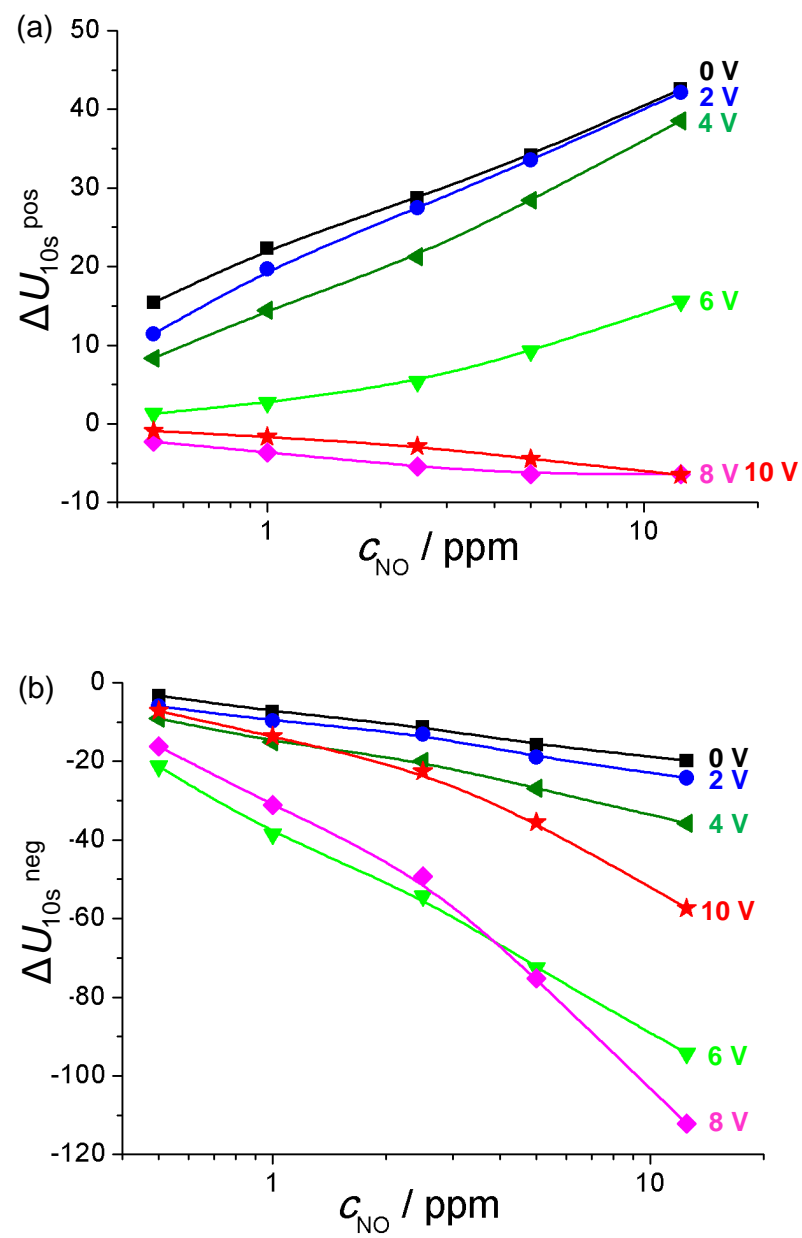

Figure 11. (a) Sensor characteristic towards small NO concentration obtained by evaluating voltage difference $\Delta U_{10 \mathrm{~s}}^{\text {pos }}$ after positive voltage pulse at various heater voltages and $T_{\text {gas }}=350^{\circ} \mathrm{C}$. (b) Sensor characteristic towards small NO concentration obtained by evaluating voltage difference $\Delta U_{10 \mathrm{~s}}^{\text {neg }}$ after negative voltage pulse at various heater voltages and $T_{\text {gas }}=350^{\circ} \mathrm{C}$.

cially at higher heater voltages as already discussed. The sensor signal $\Delta U^{*}$ at the beginning and the end of the gas dosing process is almost identical, too.

For application in exhausts with variable gas temperatures, a constant NO response in a wide temperature range is required. Therefore, the sensor temperature should be adjusted independently of the outside temperature. The resis- 


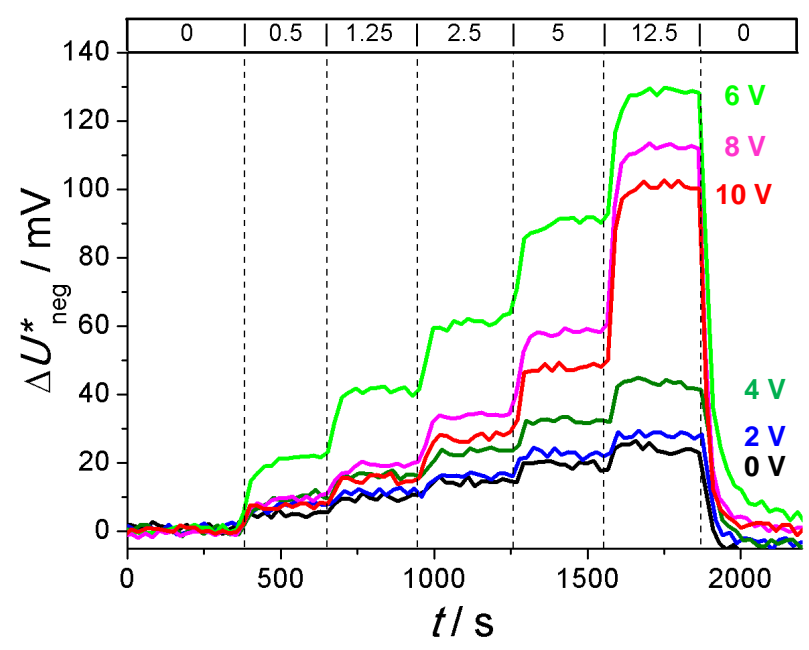

Figure 12. Sensor signal $\Delta U^{*}$ neg (for a definition, see Fig. 2) after negative voltage pulse at various heater voltages and $T_{\text {gas }}=350^{\circ} \mathrm{C}$. The dosed NO concentrations in the base gas are shown on top of the curve (in ppm).

tance (or also the impedance) between the inner electrode and the outer electrode is an obvious parameter corresponding to this sensor characteristic. According to these results, an impedance control of the lambda probe seems to further improve the applicability of the thimble-type lambda probe for NO sensing using the pulsed polarization technique.

\section{Conclusion and outlook}

The sensor operation temperature of a thimble-type lambda probe was varied by different gas temperatures as well as by different heater voltages. The sensors were operated in the pulsed polarization technique, and the discharge curves after both polarization signs as well as the sensor responses regarding low NO concentrations (10 ppm range) were evaluated in detail. According to the asymmetric sensor setup that includes a reference atmosphere at the inner electrode, the discharge curves were different for opposite polarization signs. This causes different NO response signals for both polarization signs. Impedance (or resistance) control of the sensor electrodes is suggested to compensate for exhaust gas temperature fluctuations in order to keep the NO sensitivity constant.

The robustness of the sensor in harsh exhaust gas environments offers many opportunities. However, with respect to the reference electrode, one big disadvantage is immanent in the setup: the high NO sensitivity occurs only after one polarization sign, so that the response time is not high enough: $22 \mathrm{~s}$ per polarization cycle may be too slow for automotive applications.
A further sensor development should therefore step away from the thimble-type design, but should instead use a planar symmetric design (with electrodes on each side and both electrodes facing the exhaust). Such a setup would not need a reference atmosphere. This symmetric setup should lead to a symmetric polarization and depolarization behavior, which allows the use of positive and negative polarization signs. As a result, the response time should be halved.

Edited by: J. Zosel

Reviewed by: two anonymous referees

\section{References}

Badwal, S. P. S.: Zirconia-based solid electrolytes: microstructure, stability and ionic conductivity, Solid State Ionics, 52, 23-32, 1992.

Baunach, T., Schänzlin, K., and Diehl, L.: Sauberes Abgas durch Keramiksensoren, Physik Journal, 5, 33-38, 2006 (in German).

Fergus, J. W.: Materials for high temperature electrochemical $\mathrm{NO}_{x}$ gas sensors, Sensor Actuat. B-Chem., 121, 652-663, 2007.

Fischer, S., Pohle, R., Farber, B., Proch, R., Kaniuk, J., Fleischer, M., and Moos, R.: Method for detection of NOx in exhaust gases by pulsed discharge measurements using standard zirconia-based lambda sensors, Sensor Actuat. B-Chem., 147, 780-785, 2010.

Fischer, S., Schönauer-Kamin, D., Pohle, R., Magori, E., Farber, B., Fleischer, M., and Moos, R.: $\mathrm{NO}_{x}$-detection by pulsed polarization of lambda probes, 14th International Meeting on Chemical Sensors, IMCS 14, Nuremberg, Germany, 20-23 May 2012, 1050-1053, doi:10.5162/IMCS2012/P1.6.4, 2012a.

Fischer, S., Pohle, R., Magori, E., Schönauer-Kamin, D., Fleischer, M., and Moos, R.: Pulsed Polarization of Platinum Electrodes on YSZ, Solid State Ionics, 225, 371-375, 2012 b.

Fischer, S., Schönauer-Kamin, D., Pohle, R., Fleischer, M., and Moos, R.: NO Detection by Pulsed Polarization of Lambda Probes - Influence of the Reference Atmosphere, Sensors, 13, 16051-16064, 2013.

Guth, U. and Zosel, J.: Electrochemical solid electrolyte gas sensors - hydrocarbon and $\mathrm{NO}_{x}$ analysis in exhaust gases, Ionics, 10, 366-377, 2004.

Kato, N., Nakagaki, K., and Ina, N.: Thick film $\mathrm{ZrO}_{2} \mathrm{NO}_{x}$ sensor, SAE Paper 960334, doi:10.4271/960334, 1996.

Kim, Y. W. and van Nieuwstadt, M.: Threshold monitoring of urea SCR systems, SAE Paper 2006-01-3548, doi:10.4271/2006-013548, 2006.

Moos, R.: A Brief Overview on Automotive Exhaust Gas Sensors Based on Electroceramics, Int. J. Appl. Ceram. Tec., 2, 401-413, 2005.

Moos, R.: Automotive Exhaust Gas Sensors, in: Encyclopedia of Sensors, edited by: Grimes, C. A., Dickey, E. C., and Pishko, M. V., 1, 295-312, American Scientific Publishers, Valencia, CA, USA, 2006.

Riegel, J., Neumann, H., and Wiedenmann, H.-M.: Exhaust gas sensors for automotive emission control, Solid State Ionics, 152153, 783-800, 2002.

Siegberg, D. and Kilinc, M.: Thermal and Chemical Robustness of the Smart NOx-Sensor, 12th CTI International Conference: Ex- 
haust Systems - Euro VI and Beyond - Focus on $\mathrm{CO}_{2}$ Reduction, Mainz, Germany, 28-29 January 2014.

Zhuiykov, S. and Miura, N.: Development of zirconia-based potentiometric $\mathrm{NO}_{x}$ sensors for automotive and energy industries in the early 21 st century: What are the prospects for sensors?, Sensor Actuat. B-Chem., 121, 639-651, 2007. 